\title{
Minimally invasive esophagectomy versus open esophagectomy for esophageal cancer: a meta-analysis
}

This article was published in the following Dove Press journal:

OncoTargets and Therapy

31 October 2016

Number of times this article has been viewed

Lu Lv

Weidong $\mathrm{Hu}$

Yanchen Ren

Xiaoxuan Wei

Hubei Key Laboratory of Tumor Biological Behaviors, Department of Thoracic Oncology, Hubei Cancer Clinical Study Center, Zhongnan Hospital of Wuhan University, Wuhan, Hubei, People's Republic of China
Correspondence: Weidong Hu Hubei Key Laboratory of Tumor Biological Behaviors, Department of Thoracic Oncology, Zhongnan Hospital of Wuhan University, 169 Donghu Road, Wuhan 43007I, Hubei,

People's Republic of China

Tel/fax +86 2767812860

Emailwb0013340@whu.edu.cn
Background and objectives: The safety and effectiveness of minimally invasive esophagectomy (MIE) in comparison with the open esophagectomy (OE) remain uncertain in esophageal cancer treatment. The purpose of this meta-analysis is to compare the outcomes of the two surgical modalities.

Methods: Searches were conducted in MEDLINE, EMBASE, and ClinicalTrials.gov with the following index words: "esophageal cancer", "VATS", "MIE", "thoracoscopic esophagectomy", and "open esophagectomy" for relative studies that compared the effects between MIE and OE. Random-effect models were used, and heterogeneity was assessed.

Results: A total of 20 studies were included in the analysis, consisting of four randomized controlled trials and 16 prospective studies. MIE has reduced operative blood loss $(P=0.0009)$ but increased operation time $(P=0.009)$ in comparison with OE. Patients get less respiratory complications (risk ratio $=0.74,95 \% \mathrm{CI}=0.58-0.94, P=0.01$ ) and better overall survival (hazard ratio $=0.54,95 \% \mathrm{CI}=0.42-0.70, P<0.00001)$ in the MIE group than the OE group. No statistical difference was observed between the two groups in terms of lymph node harvest, R0 resection, and other major complications.

Conclusion: MIE is a better choice for esophageal cancer because patients undergoing MIE may benefit from reduced blood loss, less respiratory complications, and also improved overall survival condition compared with OE. However, more randomized controlled trials are still needed to verify these differences.

Keywords: thoracoscopic esophagectomy, laparoscopic esophagectomy, postoperative prognosis

\section{Introduction}

Esophageal cancer is one of the most common malignant tumors of the digestive system that has a poor prognosis. ${ }^{1}$ Surgery remains to be the primary treatment for esophageal cancer; however, the open esophagectomy $(\mathrm{OE})$ is a relatively high invasive surgery, which may lead to several morbidities and prominent mortality as well. ${ }^{2}$ As a supplement to the traditional open surgery, minimally invasive esophagectomy (MIE) was first introduced to treat esophageal cancer $\sim 20$ years ago. ${ }^{3}$ With the developing skills and increasing experiences in laparoscopy and thoracoscopy in thoracic and stomach surgery, MIE has become a frequent choice for esophageal cancer nowadays. Minimally invasive surgery is assumed to reduce surgical injury on the one hand and improve patients' prognosis on the other. Guo et $\mathrm{al}^{4}$ had conducted a prospective randomized study and their results indicated that MIE had some short-term benefits such as less hemorrhage, better recovery, and fewer complications but no difference in long-term 
survival rate in comparison with open surgery. A recently randomized trial conducted by Maas et $\mathrm{al}^{5}$ suggests that MIE is associated with a better one-year quality of life compared with OE. Both studies were performed based on a small sample size, so that more evidences are needed to prove that MIE is an applicable alternative from which patients can gain more benefits compared with the open surgery. Several relevant meta-analyses had been performed to evaluate the safety and effectiveness of the two surgeries, while most of them were based on retrospective studies. Therefore, this meta-analysis was conducted through only randomized controlled trials and prospective studies in order to clarify whether MIE could improve the short-term outcomes and overall survival of patients with esophageal cancer.

\section{Methods}

\section{Data sources and literature search strategy}

Literature review was conducted by two investigators (LL and YCR) through online data sources MEDLINE, EMBASE, and ClinicalTrials.gov (up to Jan 2016), using the search terms "esophageal cancer", "VATS", "MIE", "thoracoscopic esophagectomy", "laparoscopic esophagectomy", and "Open esophagectomy".

\section{Study selection}

Inclusion criteria were: 1) randomized controlled trials or prospective studies; 2) patients who underwent esophagectomy for esophageal cancer; 3) comparing MIE with OE on interest outcomes such as surgical results, postoperative complications, and survival rate; 4) research of human beings; and 5) written in English language.

\section{Study quality assessment}

The quality of the studies was assessed by The NewcastleOttawa quality assessment Scale (NOS), and the total score of each study should not be $<6$, which is considered as high quality and eligible for the research.

\section{Data extraction}

The data on characteristics of studies, surgical outcomes, postoperative complications, and overall survival were extracted from the selected studies by one author (LL) and checked by another author (XXW). Information included are study name, publication year, study design, number of patients, interventions, age, sex, tumor stage, tumor location, pathology, operative time, operation blood loss, numbers of lymph node harvest, $\mathrm{R} 0$ resection, reoperation, in-hospital mortality, respiratory complications, cardiovascular complications, anastomotic leakage, anastomotic stricture, chylothorax recurrent laryngeal paralysis, and overall survival.

\section{Statistical analysis}

Review Manager Version 5.3 was used to perform metaanalysis, and the estimated survival data were obtained from the Kaplan-Meier curves using GetData Graph Digitizer software. The data can be synthesized only when the number of studies exceeds two. Measurement data reported as mean $\pm \mathrm{SD}$ were adopted, and odds ratio (OR) or risk ratio (RR) was calculated. Pooled weighted mean difference (WMD) was used in enumeration data and hazard ratio in survival data. All the statistical results use random-effect models. Heterogeneity was assessed by $\chi^{2}$ and $I^{2}$ and publication bias by funnel plots. The subgroup analysis was performed based on the study design.

\section{Results}

\section{Eligible studies and characteristics of studies}

In this meta-analysis, 20 studies were included, four randomized controlled trials and 16 prospective studies (Figure 1). A total of 6,025 patients were joined into research, of whom 2,091(35\%) underwent MIE and 3,934 (65\%) underwent OE. The characteristics of the studies are shown in Table 1.

\section{Meta-analysis of postoperative outcomes Surgical outcomes}

MIE group has lower operative blood loss (WMD $=-283.61$, 95\% CI $=-451.69$ to $-115.52, P=0.0009$; Figure $2 \mathrm{~A}$ ) and longer operation time $(\mathrm{WMD}=44.42,95 \% \mathrm{CI}=10.95-77.88$, $P=0.009$; Figure $2 \mathrm{~B}$ ) than the $\mathrm{OE}$ group. There are no statistical significances of lymph node harvest $(\mathrm{WMD}=-0.80$, 95\% CI $=-4.63-3.03, P=0.68$; Figure 2C), R0 resection $(\mathrm{RR}=1.03,95 \% \mathrm{CI}=0.98-1.08, P=0.21$; Figure $2 \mathrm{D})$ between the two groups.

\section{Postoperative complications}

Patients in the MIE group get less respiratory complications than in the OE group $(\mathrm{RR}=0.74,95 \% \mathrm{CI}=0.58-0.94$, $P=0.01)$ and in the randomized-controlled trial (RCT) studies subgroup $(\mathrm{RR}=0.34,95 \% \mathrm{CI}=0.21-0.53, P=0.01$, $P<0.00001)$, while in the prospective studies subgroup $(\mathrm{RR}=0.83,95 \% \mathrm{CI}=0.67-1.04, P=0.11$; Figure 3$)$. There are no statistical significances of anastomotic leakage $(\mathrm{OR}=0.84$, $95 \% \mathrm{CI}=0.59-1.18, P=0.32$; Figure 4 ), anastomotic stricture ( $\mathrm{OR}=1.76,95 \% \mathrm{CI}=0.78-3.97, P=0.18$; Figure 5A), inhospital mortality $(\mathrm{OR}=0.84,95 \% \mathrm{CI}=0.60-1.19, P=0.33$; 


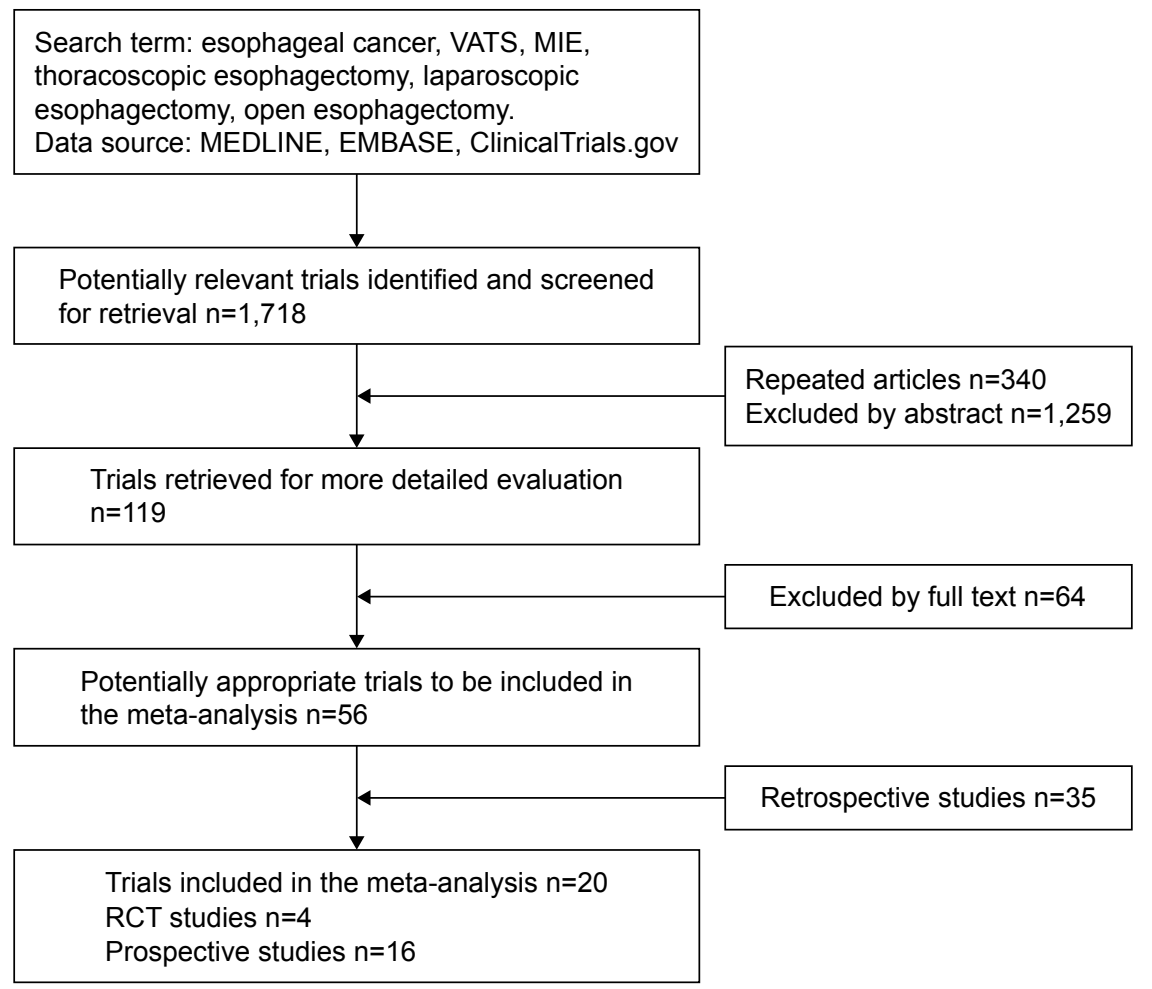

Figure I Stages of the systematic review of the trials.

Abbreviations: MIE, minimally invasive esophagectomy; RCT, randomized controlled trial.

Figure 5B), reoperation $(\mathrm{OR}=1.10,95 \% \mathrm{CI}=0.59-2.04$, $P=0.77$; Figure 5C), cardiovascular complications $(\mathrm{OR}=0.90$, 95\% CI =0.64-1.28, $P=0.57$; Figure 6A), chylothorax ( $\mathrm{OR}=0.90,95 \% \mathrm{CI}=0.47-1.74, P=0.76$; Figure $6 \mathrm{~B})$, and recurrent laryngeal paralysis $(\mathrm{OR}=1.31,95 \% \mathrm{CI}=0.67-2.55$, $P=0.43$; Figure 6C) between the two groups.

\section{Survival outcome}

The MIE group has a better overall survival than the open group (hazard ratio $=0.54,95 \% \mathrm{CI}=0.42-0.70, P<0.00001$; Figure 7).

All outcomes of interest are listed in Table 2, and the funnel plots display the publication bias of respiratory complications (Figure 8A), cardiovascular complications (Figure 8B), in-hospital mortality (Figure 8C), and anastomotic leakage (Figure 8D).

\section{Discussion}

The MIE was first introduced in 1980s, and the study of Cuschieri et $\mathrm{al}^{3}$ indicated that MIE was as effective as open surgery. In the last 20 years, with the sophisticated technique of thoracoscope and laparoscope, minimally invasive surgery shows significant superiority in reducing surgical injury and increasing survival rate in thoracic and abdominal operations. ${ }^{6,7}$ Now, MIE has been used more and more frequently in esophageal cancer, as it has been considered as a good method to reduce the high morbidity and mortality compared with the traditional OE. There are two major operation methods of MIE, including combined thoracoscopic-laparoscopic esophagectomy, which is also known as total MIE and thoracoscopic-assisted esophagectomy or laparoscopic-assisted esophagectomy - the so-called hybrid MIE. This study compared the open surgery with both hybrid MIE and total MIE. Due to the complexity of the esophagectomy, different surgery modalities might lead to various surgical complications, but the main morbidities are pulmonary complications, cardiac complications, anastomotic complications, and so forth. Therefore, the focus was on comparing the postoperative outcomes as mentioned earlier.

The studies about the comparison of the two surgeries are primarily retrospective studies as most of the clinical trials that are registered in ClinicalTrials.gov are still unfinished. So far, only four randomized studies have done their jobs and that is the reason why the majority of the existed metaanalyses were based on retrospective studies. Among those meta-analyses that had been done before us: Sgourakis et $\mathrm{al}^{8}$ compared postoperative outcomes and survival between MIE and OE and revealed that both groups have the same 


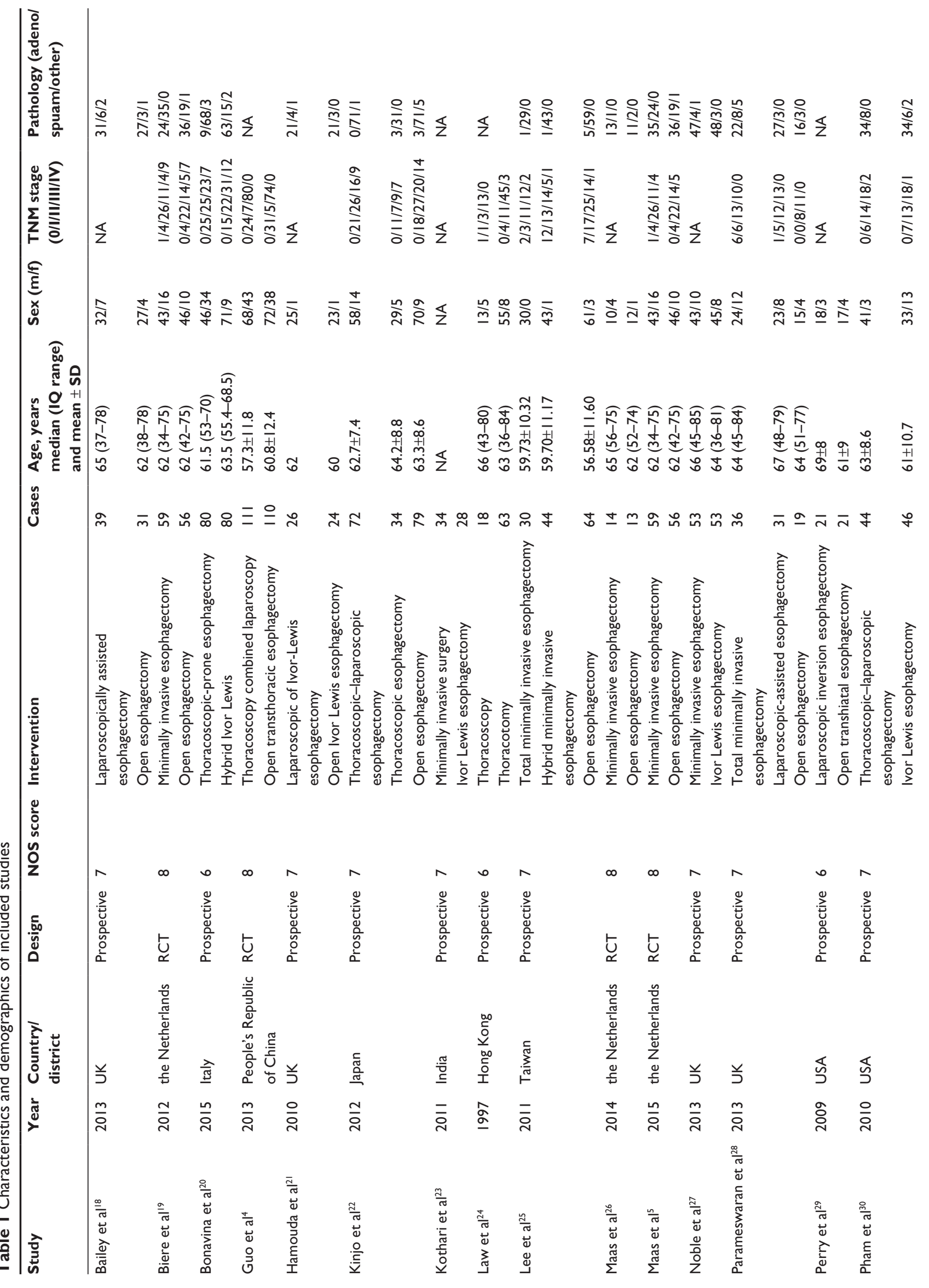




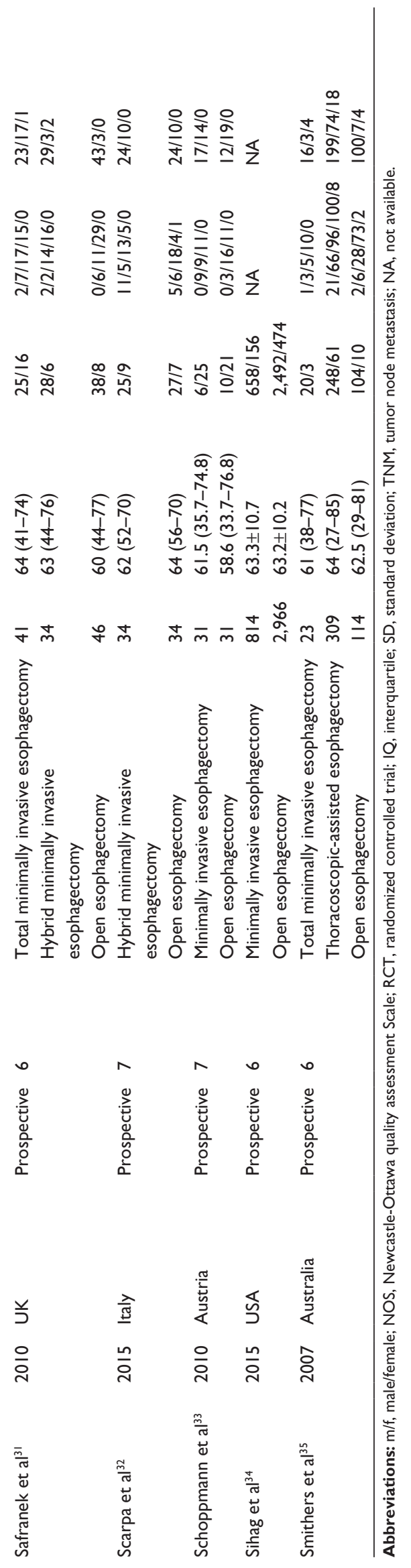

in-hospital results and prognosis; Nagpal et $\mathrm{al}^{9}$ analyzed postoperative outcomes, including the 30-day mortality and anastomotic leakage of MIE and OE and revealed that there was no significant difference in the mortality; Zhou et al $1^{10,11}$ compared anastomotic leakage and in-hospital mortality between the two groups, and the outcome showed that MIE has superiority over OE as the former could reduce the inhospital mortality rate; however, there was no evidence that MIE could decrease the anastomotic leakage; and Guo et al ${ }^{12}$ indicated that MIE can achieve significant long-term survival rates and reduce perioperative complications.

In this study, only randomized trials and prospective studies were included, totally 20 studies were pooled to compare the outcomes between MIE and OE. Though Xiong et $a l^{13}$ had done a similar work before us, they included only three RCTs and two prospective studies. Therefore, our evidence is more sufficient and reliable. The results showed that MIE had advantage in reducing the operative blood loss, but the outcome has great heterogeneity $\left(I^{2}=87 \%\right)$ that may be attributable to the following reasons: first, there are various approaches in both MIE and OE, and the surgery styles vary from one operation team to another as well. Second, most of the studies use the median \pm interquartile range, instead of mean $\pm \mathrm{SD}$, which is unavailable to run meta-analysis, that in turn influences the result of synthesis. Patients undergoing MIE get less respiratory complications than OE. In order to figure out the source of its heterogeneity $\left(I^{2}=67 \%\right)$ we did a subgroup analysis. The heterogeneity is much more significant in the subgroup of prospective studies $\left(I^{2}=57 \%\right)$ than that in the prospective studies $\left(I^{2}=0 \%\right)$, and it suggests that the study design is the main cause of heterogeneity. Respiratory morbidities, especially pulmonary complications, which are the most important factors, could impact the prognosis of the patients. A lot of patients get dysfunctions of respiratory system after esophagectomy. ${ }^{14-17}$ The reasons that MIE can reduce respiratory complications might be as follows: first, the exquisite operation procedure could decrease the surgical trauma and do less harm to the chest wall or pulmonary tissues. Next, less surgical injury can free the patients from the pain followed by and postoperative pain makes patients less willing to cough, which aggravates the pulmonary infection. The results demonstrated that there are no statistical differences with respect to number of lymph nodes harvest, $\mathrm{R} 0$ resection, reoperation, in-hospital mortality, cardiovascular complications, anastomotic leakage, anastomotic stricture, chylothorax, and recurrent laryngeal paralysis between the two groups, but the MIE group has a better overall survival than the open group. The reason could be explained by the 
A

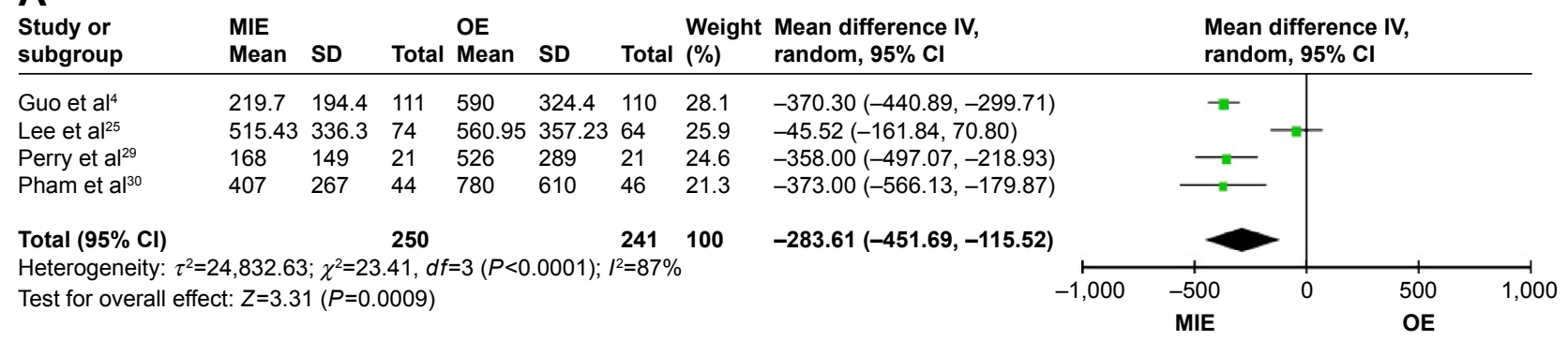

\section{B}

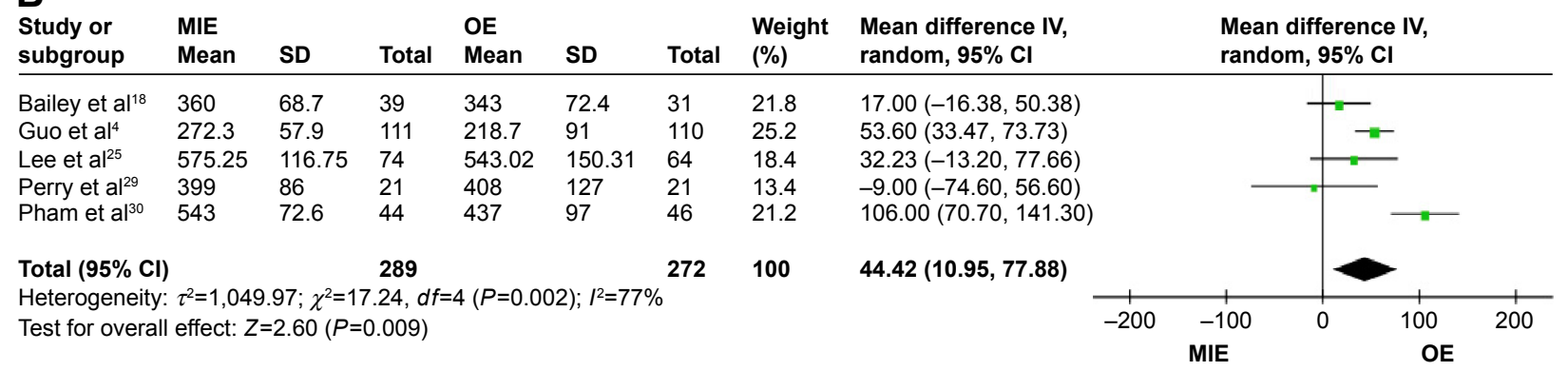

c

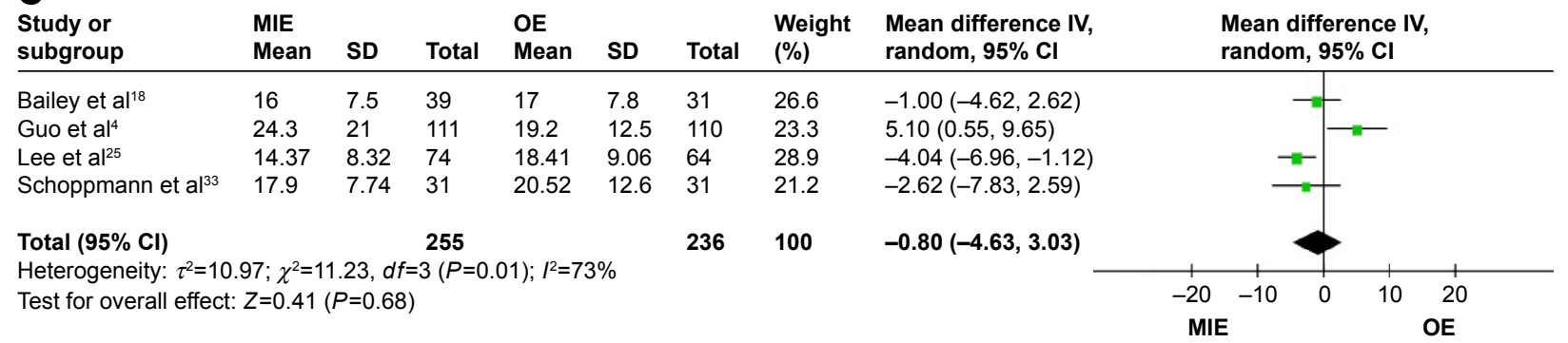

D

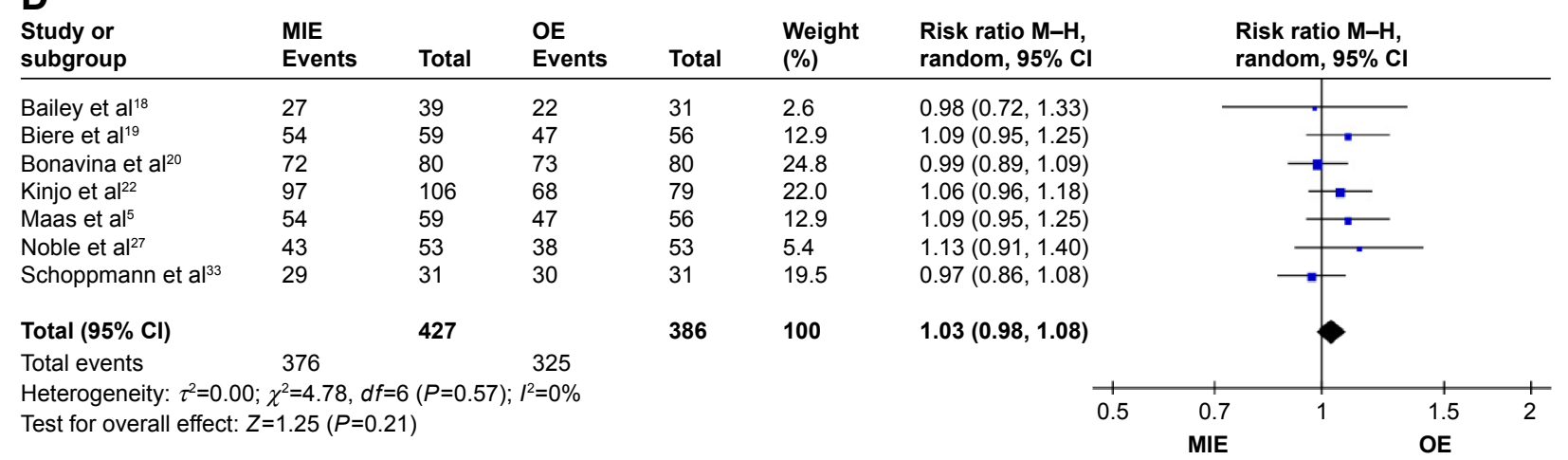

Figure 2 Forest plots of surgical outcomes.

Notes: (A) Forest plots of blood loss. (B) Forest plots of operation time. (C) Forest plots of number of lymph nodes harvest. (D) Forest plots of R0 resection. Abbreviations: $\mathrm{Cl}$, confidence interval; M-H, Mantel-Haenszel; MIE, minimally invasive esophagectomy; OE, open esophagectomy.

amplification effect of the thoracoscope or laparoscope, through which the tumor tissues and relevant lymph nodes could be dissected more accurately; therefore, the MIE can get a better prognosis.

This study has also some limitations. In the first place, except for operation blood loss and operative time, there were significant heterogeneities in number of lymph nodes harvest, reoperation, and anastomotic stricture. The reasons resemble those explained in operation blood loss. In the second place, several included studies did not report the outcomes completely, yet access to the original data was unavailable. Finally, lack of large, multiple center, randomized-controlled trials might reduce the effectiveness of the research. Therefore, the work needs to be improved when there are more RCTs. 


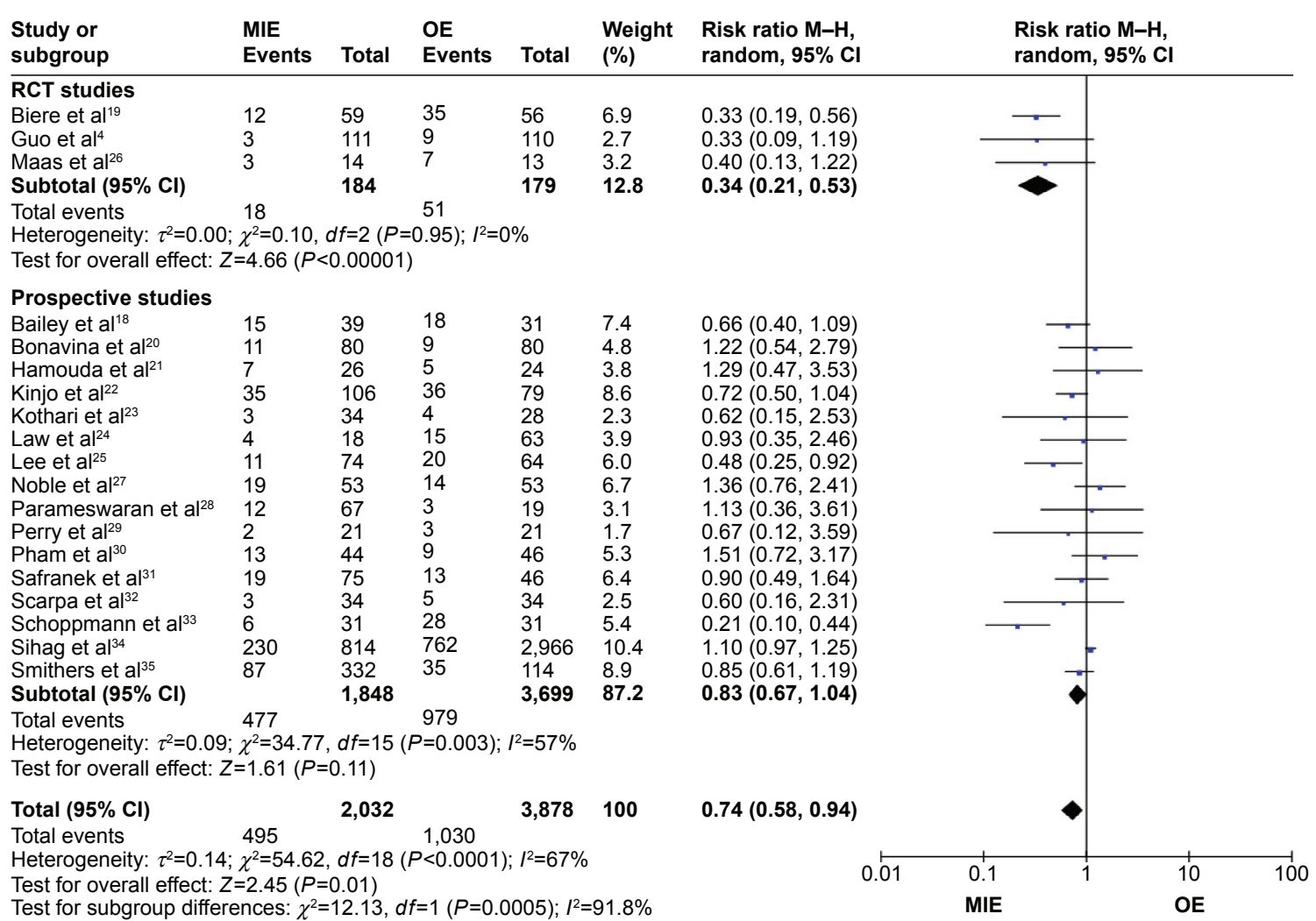

Figure 3 Forest plot of respiratory complications.

Abbreviations: $\mathrm{Cl}$, confidence interval; $\mathrm{M}-\mathrm{H}$, Mantel-Haenszel; MIE, minimally invasive esophagectomy; OE, open esophagectomy; RCT, randomized controlled trial.

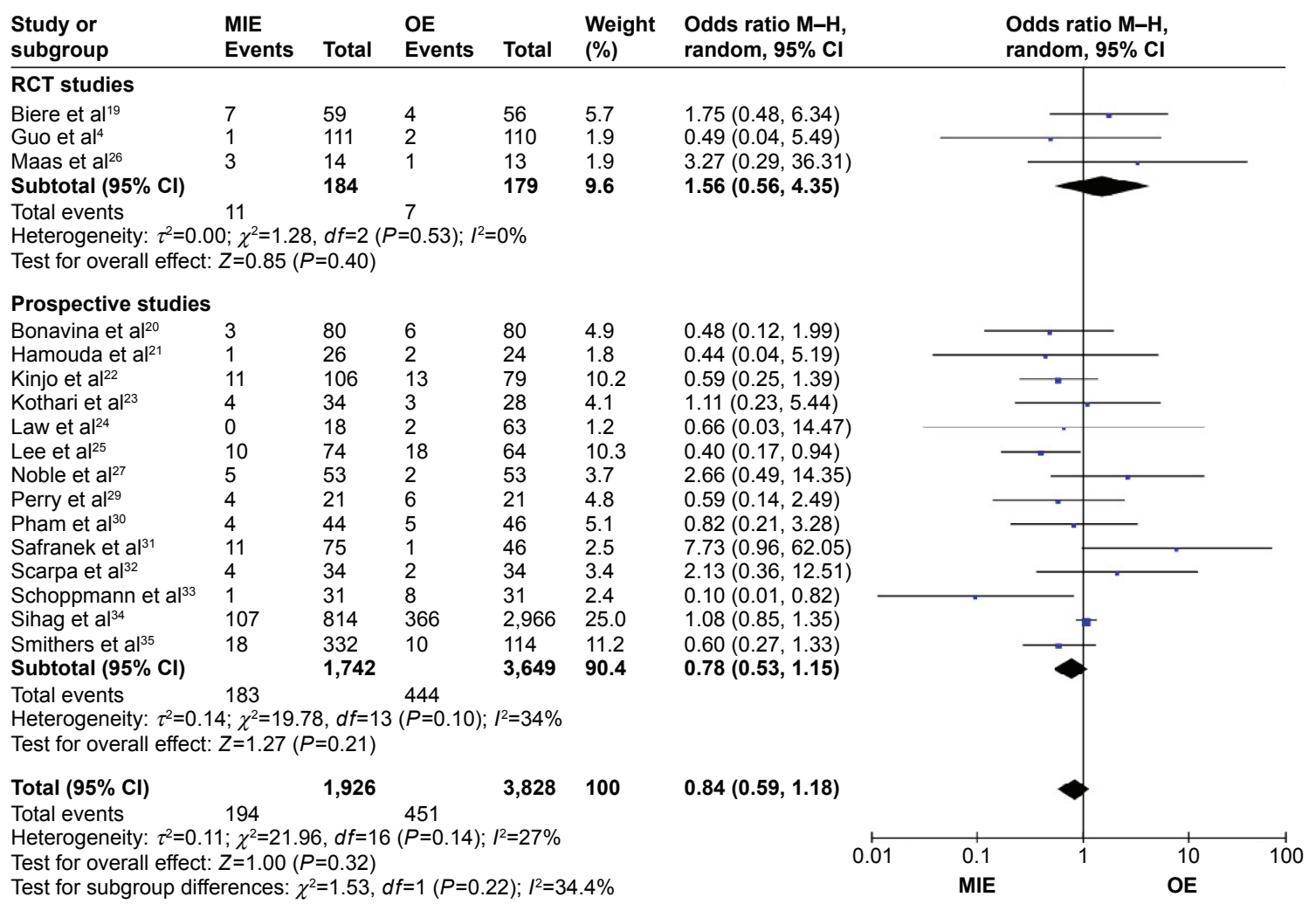

Figure 4 Forest plot of anastomotic leakage.

Abbreviations: $\mathrm{Cl}$, confidence interval; $\mathrm{M}-\mathrm{H}$, Mantel-Haenszel; MIE, minimally invasive esophagectomy; OE, open esophagectomy; RCT, randomized controlled trial. 
A

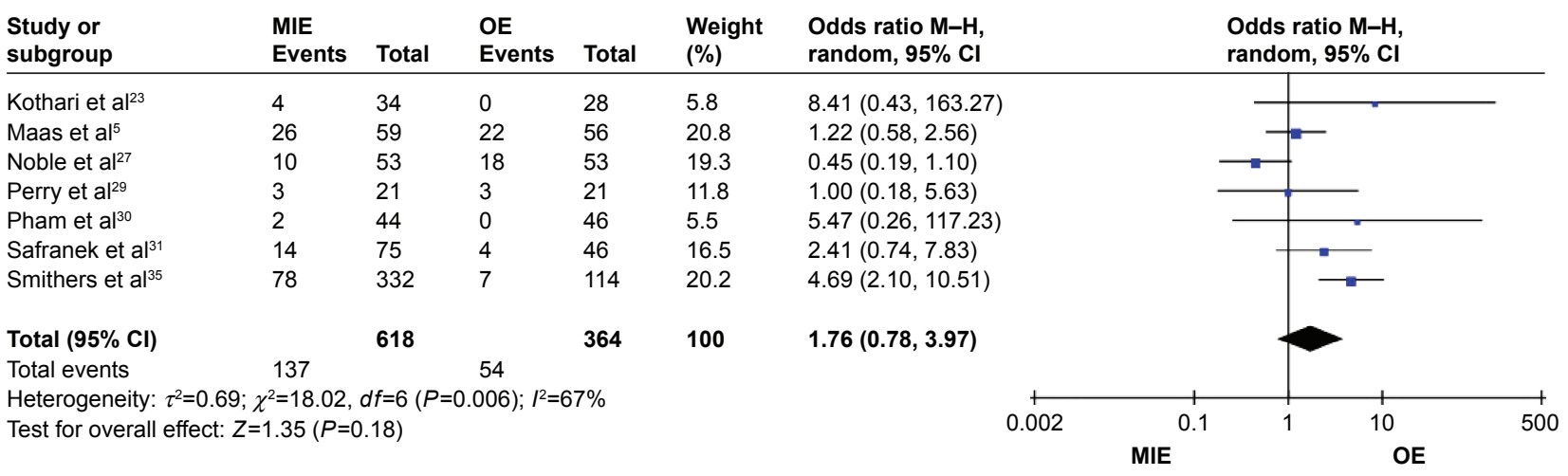

B

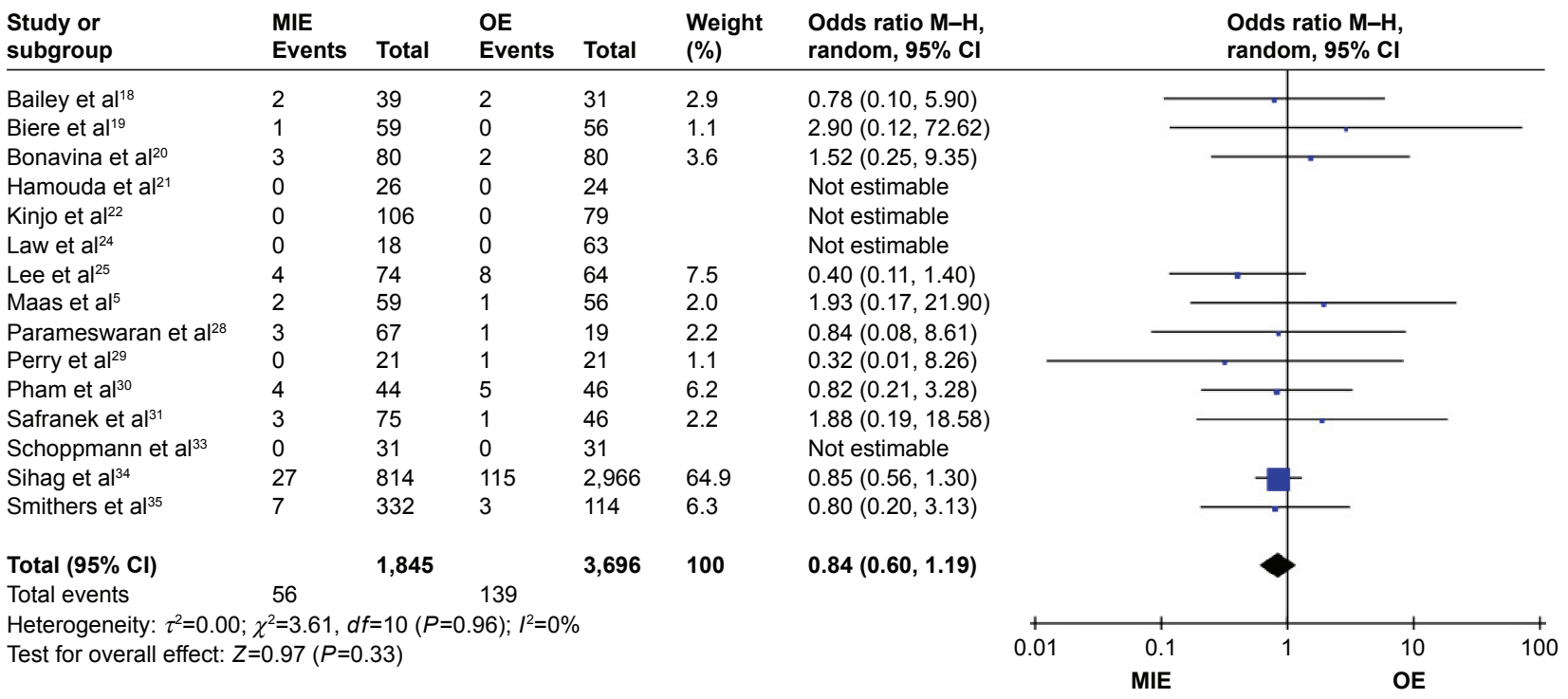

C

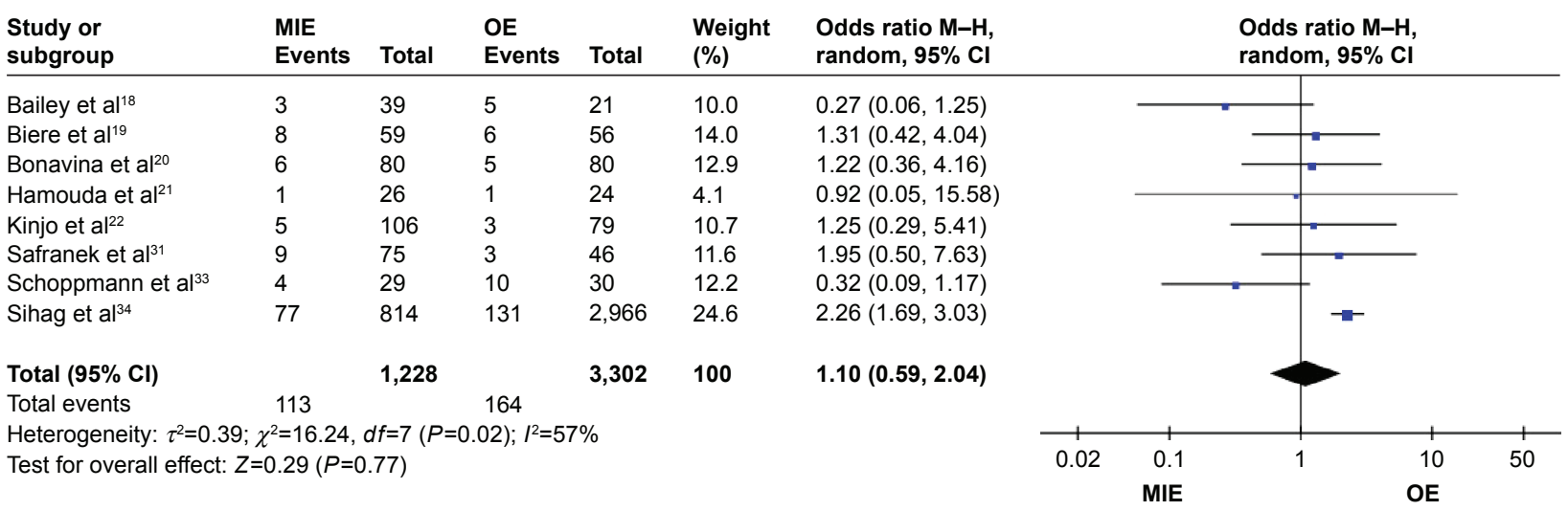

Figure 5 Forest plots of anastomotic stricture, in-hospital mortality, and reoperation.

Notes: (A) Forest plots of anastomotic stricture. (B) Forest plots of in-hospital mortality. (C) Forest plots of reoperation.

Abbreviations: $\mathrm{Cl}$, confidence interval; $\mathrm{M}-\mathrm{H}$, Mantel-Haenszel; MIE, minimally invasive esophagectomy; OE, open esophagectomy. 
A

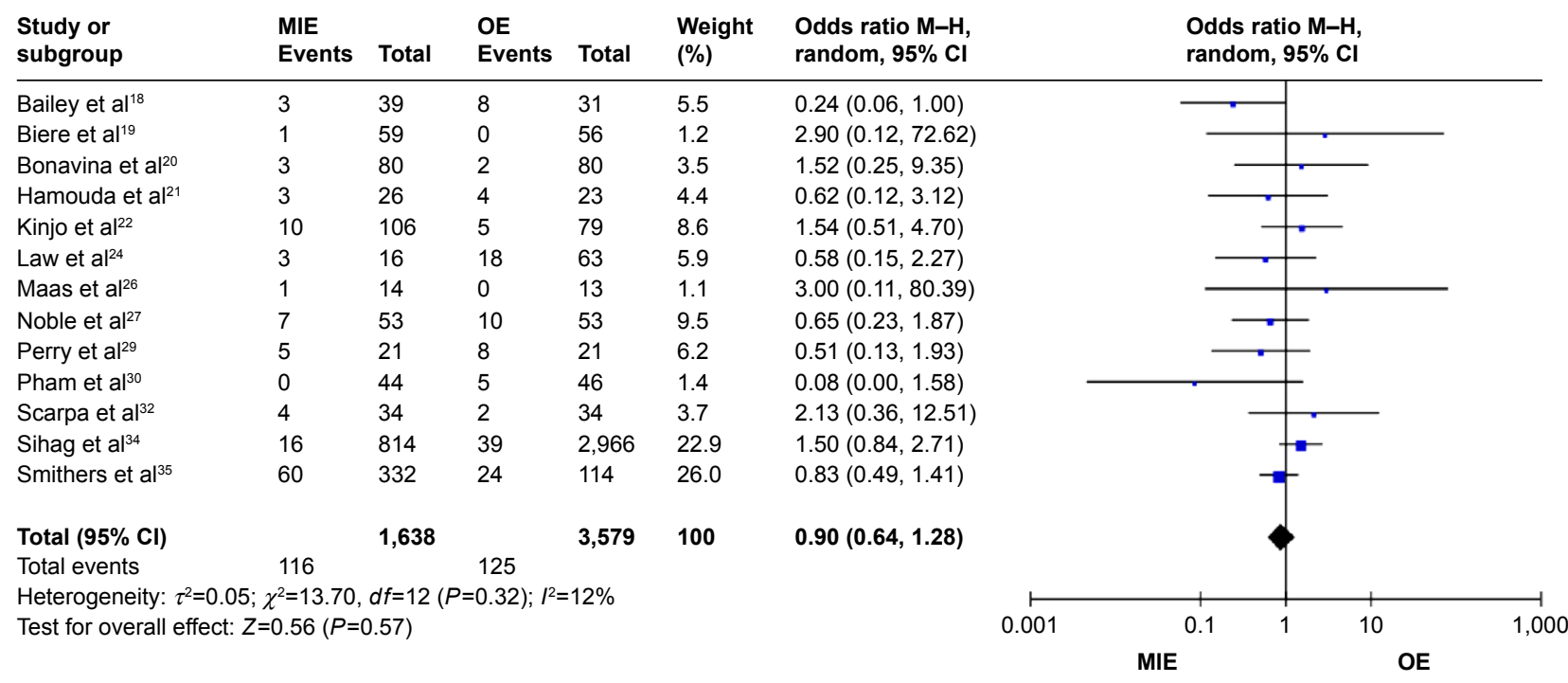

\section{B}

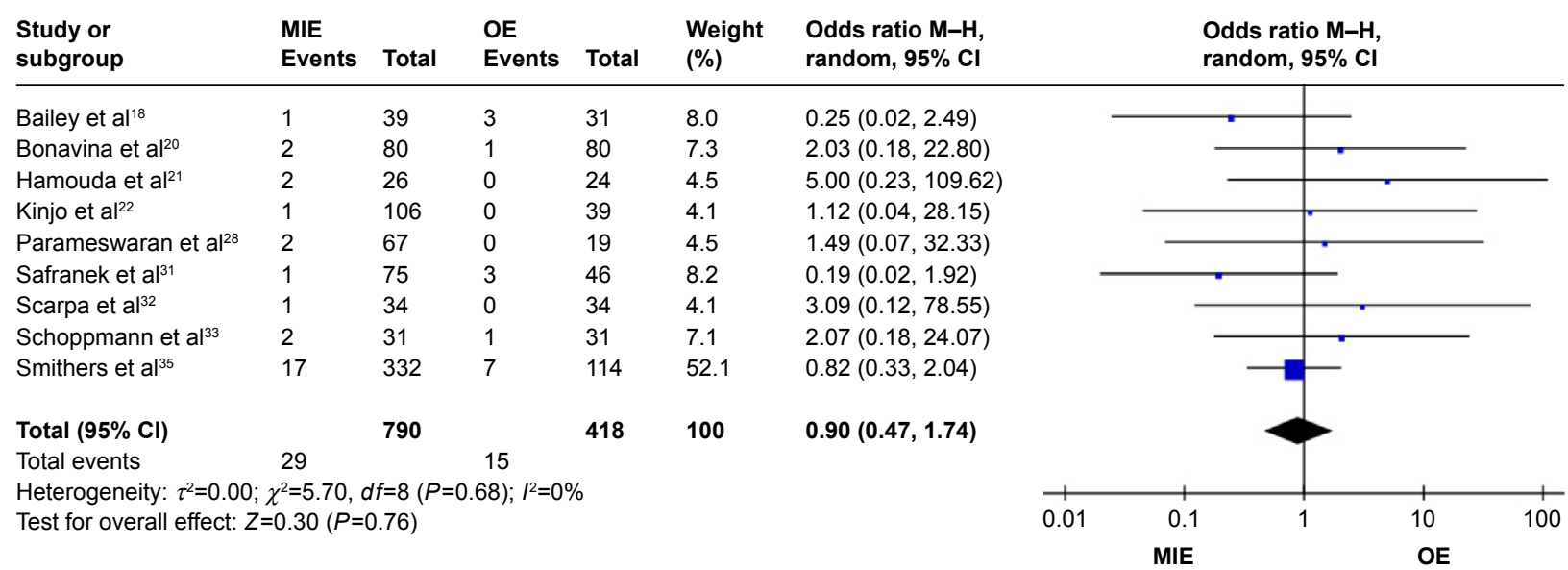

C

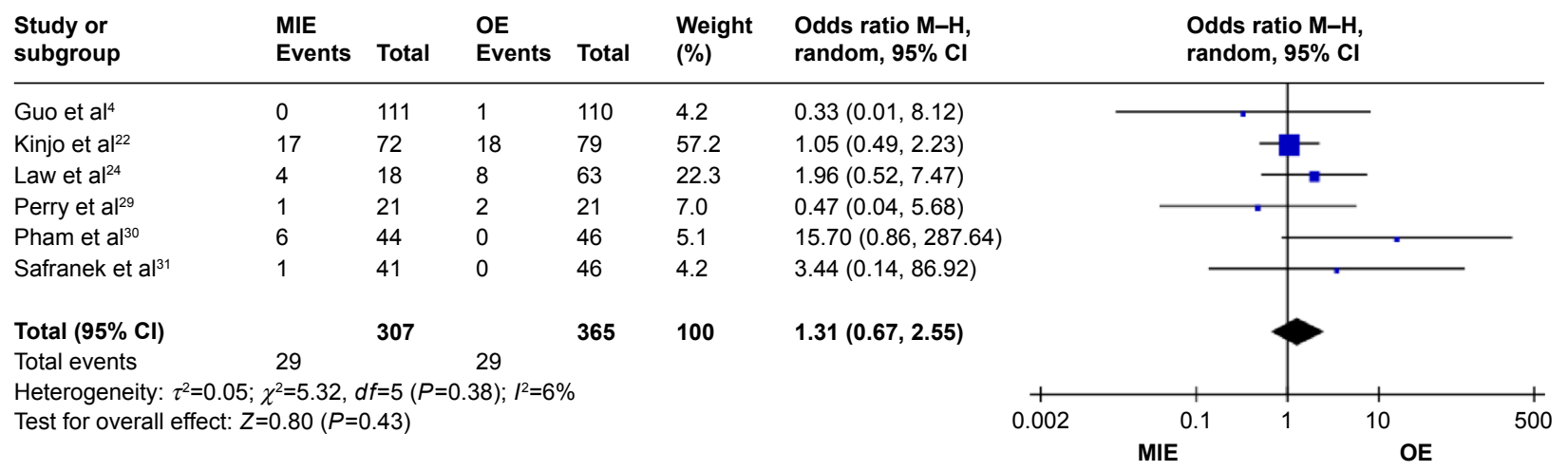

Figure 6 Forest plots of cardiovascular complications, chylothorax, and recurrent laryngeal paralysis.

Notes: (A) Forest plots of cardiovascular complications. (B) Forest plots of chylothorax. (C) Forest plots of recurrent laryngeal paralysis.

Abbreviations: $\mathrm{Cl}$, confidence interval; $\mathrm{M}-\mathrm{H}$, Mantel-Haenszel; MIE, minimally invasive esophagectomy; OE, open esophagectomy. 


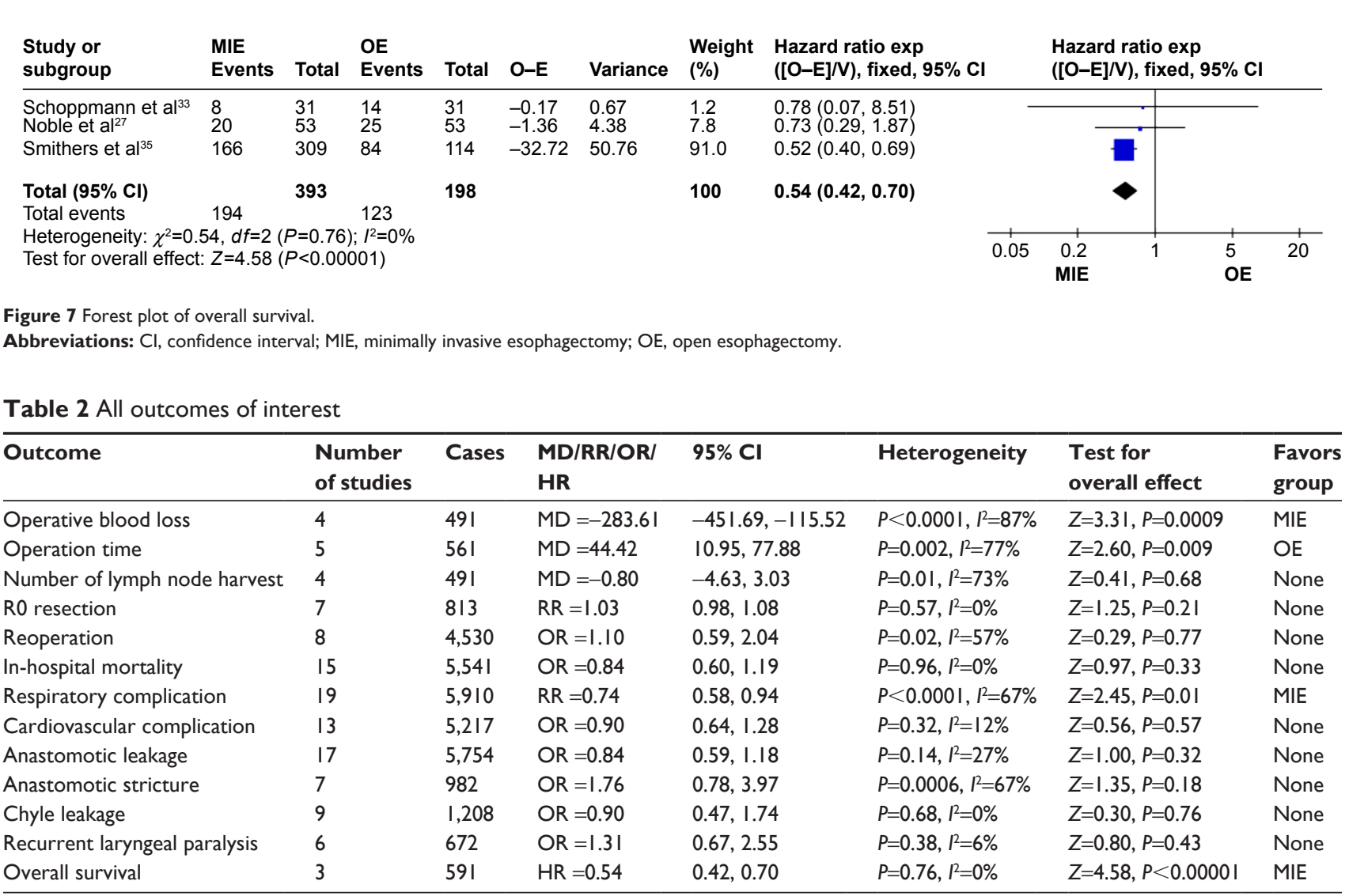

Abbreviations: $\mathrm{Cl}$, confidence interval; RR, relative ratio; OR, odds ratio; HR, hazard ratio; $\mathrm{MD}$, mean difference; MIE, minimally invasive esophagectomy; OE, open esophagectomy.

A

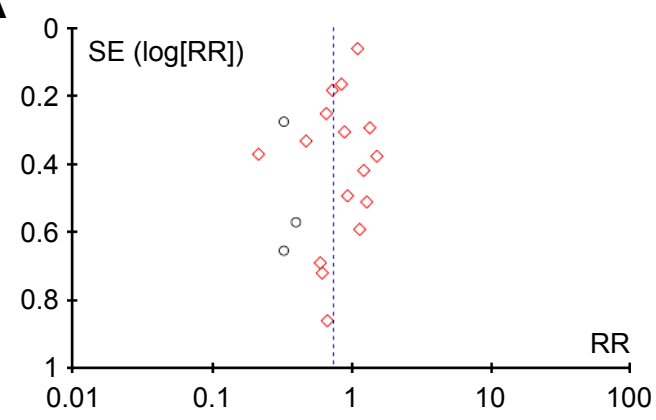

C

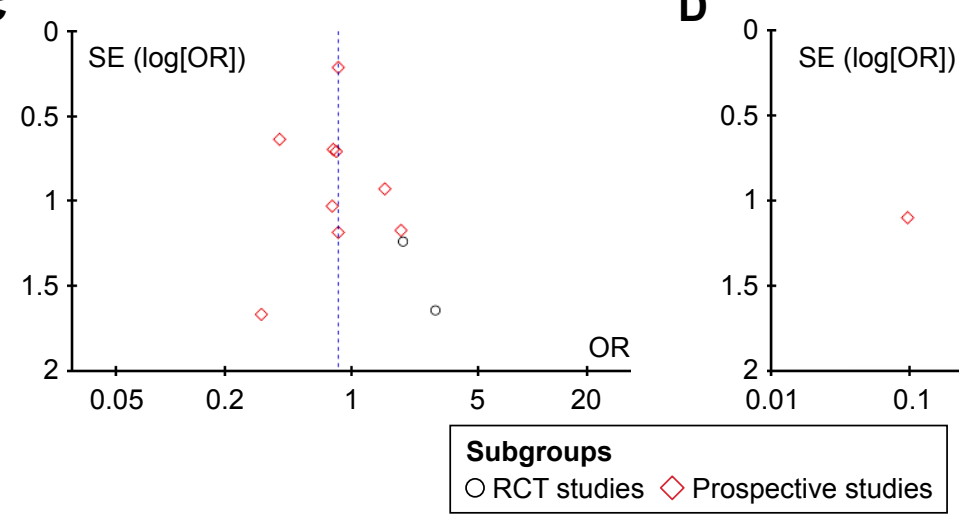

B
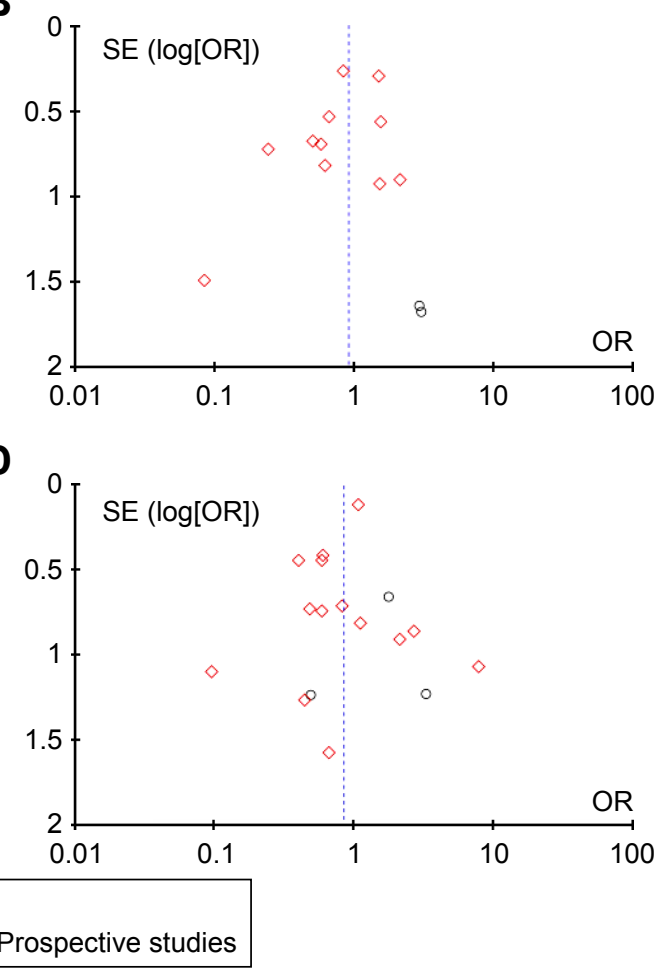

Figure 8 Funnel plots of postoperative complications.

Notes: (A) Funnel plots of respiratory complications. (B) Funnel plots of cardiovascular complications. (C) Funnel plots of in-hospital mortality. (D) Funnel plots of anastomotic leakage.

Abbreviations: $\mathrm{OR}$, odds ratio; $\mathrm{RR}$, relative ratio; $\mathrm{RCT}$, randomized controlled trial; $\mathrm{SE}$, standard error. 


\section{Conclusion}

Patients who have undergone the MIE have lower blood loss and less respiratory complications in comparison with the OE. They can also gain the same benefits of postoperative outcomes composing lymph node harvest and margin of resection as the open group. The estimated overall survival rate is improved in the MIE group. That being said, MIE is a better choice for esophageal cancer patients.

\section{Disclosure}

The authors report no conflicts of interest in this work.

\section{References}

1. DeSantis CE, Lin CC, Mariotto AB, et al. Cancer treatment and survivorship statistics, 2014. CA Cancer J Clin. 2014;64(4):252-271.

2. Jamieson GG, Mathew G, Ludemann R, et al. Postoperative mortality following oesophagectomy and problem in reporting its rate. Br J Surg. 2004;91(8):943-947.

3. Cuschieri A, Shimi S, Banting S. Endoscopic oesophagectomy through a right thoracoscopic approach. J R Coll Surg Edinb. 1992;37(1):7-11.

4. Guo M, Xie B, Sun X, et al. A comparative study of the therapeutic effect in two protocols: video-assisted thoracic surgery combined with laparoscopy versus right open transthoracic esophagectomy for esophageal cancer management. Chin German J Clin Oncol. 2013;12:68-71.

5. Maas KW, Cuesta MA, van Berge Henegouwen MI, et al. Quality of life and late complications after minimally invasive compared to open esophagectomy: results of a randomized trial. World J Surg. 2015;39(8):1986-1993.

6. Veldkamp R, Kuhry E, Hop WC, et al. Laparoscopic surgery versus open surgery for colon cancer: short-term outcomes of a randomized trial. Lancet Oncol. 2005;6(7):477-484.

7. Luketich JD, Pennathur A, Franchetti Y, et al. Minimally invasive esophagectomy: results of a prospective phase II multicenter trial-the eastern cooperative oncology group (E2202) study. Ann Surg. 2015; 261(4):702-707.

8. Sgourakis G, Gockel I, Radtke A, et al. Minimally invasive versus open esophagectomy: meta-analysis of outcomes. Dig Dis Sci. 2010 55(11):3031-3040.

9. Nagpal K, Ahmed K, Vats A, et al. Is minimally invasive surgery beneficial in the management of esophageal cancer? A meta-analysis. Surg Endosc. 2010;24(7):1621-1629.

10. Zhou C, Zhang L, Wang H, et al. Superiority of minimally invasive oesophagectomy in reducing in-hospital mortality of patients with resectable oesophageal cancer: a meta-analysis. PLoS One. 2015;10(7):e0132889.

11. Zhou C, Ma G, Li X, et al. Is minimally invasive esophagectomy effective for preventing anastomotic leakages after esophagectomy for cancer? A systematic review and meta-analysis. World J Surg Oncol. 2015;13:269-278.

12. Guo W, Ma X, Yang S, et al. Combined thoracoscopic-laparoscopic esophagectomy versus open esophagectomy: a meta-analysis of outcomes. Surg Endosc. Epub 2015 Dec 10.

13. Xiong WL, Li R, Lei HK, Jiang ZY. Comparison of outcomes between minimally invasive oesophagectomy and open oesophagectomy for oesophageal cancer. ANZ J Surg. Epub 2015 Oct 19.

14. Jiao WJ, Wang TY, Gong M, Pan H, Liu YB, Liu ZH. Pulmonary complications in patients with chronic obstructive pulmonary disease following transthoracic esophagectomy. World J Gastroenterol. 2006; 12(16):2505-2509.

15. Avendano CE, Flume PA, Silvestri GA, King LB, Reed CE. Pulmonary complications after esophagectomy. Ann Thorac Surg. 2002; 73(3):922-926.
16. Nakamura M, Iwahashi M, Nakamori M, et al. An analysis of the factors contributing to a reduction in the incidence of pulmonary complications following an esophagectomy for esophageal cancer. Langenbecks Arch Surg. 2008;393(2):127-133.

17. Luketich JD, Schaner PR, Christie NA, et al. Minimally invasive esophagectomy. Ann Thorac Surg. 2000;70(3):906-911.

18. Bailey L, Khan O, Willows E, Somers S, Mercer S, Toh S. Open and laparoscopically assisted oesophagectomy: a prospective comparative study. Eur J Cardiothorac Surg. 2013;43(2):268-273.

19. Biere SS, van Berge Henegouwen MI, Maas KW, et al. Minimally invasive versus open oesophagectomy for patients with oesophageal cancer: a multicentre, open-label, randomised controlled trial. Lancet. 2012;379(9829):465-466.

20. Bonavina L, Scolari F, Aiolfi A, et al. Early outcome of thoracoscopic and hybrid esophagectomy: propensity-matched comparative analysis. Surgery. 2015;159(4):1073-1081.

21. Hamouda AH, Forshaw MJ, Tsigritis K, et al. Perioperative outcomes after transition from conventional to minimally invasive Ivor-Lewis esophagectomy in a specialized center. Surg Endosc. 2010;24(4):865-869.

22. Kinjo Y, Kurita N, Nakamura F, et al. Effectiveness of combined thoracoscopic-laparoscopic esophagectomy: comparison of postoperative complications and midterm oncological outcomes in patients with esophageal cancer. Surg Endosc. 2012;26(2):381-390.

23. Kothari KC, Nair CK, George PS, Patel MH, Gatti RC, Gurjar GC. Comparison of esophagectomy with and without thoracotomy in a lowresource tertiary care center in a developing country. Dis Esophagus. 2011;24(8):583-589.

24. Law S, Fok M, Chu KM, Wong J. Thoracoscopic esophagectomy for esophageal cancer. Surgery. 1997;122(1):8-14.

25. Lee JM, Cheng JW, Lin MT, Huang PM, Chen JS, Lee YC. Is there any benefit to incorporating a laparoscopic procedure into minimally invasive esophagectomy? The impact on perioperative results in patients with esophageal cancer. World J Surg. 2011;35(4):790-797.

26. Maas KW, Biere SS, van Hoogstraten IM, van der Peet DL, Cuesta MA. Immunological changes after minimally invasive or conventional esophageal resection for cancer: a randomized trial. World J Surg. 2014; 38(1):131-137.

27. Noble F, Kelly JJ, Bailey IS, Byrne JP, Underwood TJ; South Coast Cancer Collaboration - Oesophago-Gastric (SC3-OG). A prospective comparison of totally minimally invasive versus open Ivor Lewis esophagectomy. Dis Esophagus. 2013;26(3):263-271.

28. Parameswaran R, Titcomb DR, Blencow NS, et al. Assessment and comparison of recovery after open and minimally invasive esophagectomy for cancer: an exploratory study in two centers. Ann Surg Oncol. 2013;20(6):1970-1977.

29. Perry KA, Enestvedt CK, Pham T, et al. Comparison of laparoscopic inversion esophagectomy and open transhiatal esophagectomy for high-grade dysplasia and stage I esophageal adenocarcinoma. Arch Surg. 2009;144(7):679-684.

30. Pham TH, Perry KA, Dolan JP, et al. Comparison of perioperative outcomes after combined thoracoscopic-laparoscopic esophagectomy and open Ivor-Lewis esophagectomy. Am J Surg. 2010;199(5):594-598.

31. Safranek PM, Cubitt J, Booth MI, Dehn TC. Review of open and minimal access approaches to oesophagectomy for cancer. Br J Surg. 2010;97(12):1845-1853.

32. Scarpa M, Cavallin F, Saadeh LM, et al. Hybrid minimally invasive esophagectomy for cancer: impact on postoperative inflammatory and nutritional status. Dis Esophagus. Epub 2015 Sep 24.

33. Schoppmann SF, Prager G, Langer FB, et al. Open versus minimally invasive esophagectomy: a single-center case controlled study. Surg Endosc. 2010;24(12):3044-3053.

34. Sihag S, Kosinski AS, Gaissert HA, Wright CD, Schipper PH. Minimally invasive versus open esophagectomy for esophageal cancer: a comparison of early surgical outcomes from the Society of Thoracic Surgeons National Database. Ann Thorac Surg. 2015;78(4):627-633.

35. Smithers BM, Gotley DC, Martin I, Thomas JM. Comparison of the outcomes between open and minimally invasive esophagectomy. Ann Surg. 2007;245(2):232-240. 


\section{Publish your work in this journal}

OncoTargets and Therapy is an international, peer-reviewed, open access journal focusing on the pathological basis of all cancers, potential targets for therapy and treatment protocols employed to improve the management of cancer patients. The journal also focuses on the impact of management programs and new therapeutic agents and protocols on

patient perspectives such as quality of life, adherence and satisfaction. The manuscript management system is completely online and includes a very quick and fair peer-review system, which is all easy to use. Visit http://www.dovepress.com/testimonials.php to read real quotes from published authors.

Submit your manuscript here: http://www.dovepress.com/oncotargets-and-therapy-journal 